\title{
Prediction of S-1-induced anemia
}

\author{
Hyun Cheol Chung \\ Yonsei Cancer Center, Cancer Metastasis Research Center, Yonsei University College of Medicine, 134 Shinchon-dong, Seodaemun-gu, \\ Seoul 120-752, Korea
}

\begin{abstract}
S-1, a novel oral fluoropyrimidine, has shown remarkably good tolerability in Korean gastric and colorectal cancer patients due to its favorable safety profile. Myelosuppression and diarrhea were the events that precluded dose escalation in Japan, whereas gastrointestinal toxicity and skin reaction were the major limiting factors in Western countries. In contrast, the major adverse event in Korean patients was anemia, which appeared early in the S-1 treatment period and varied among patients. Conventional comparative genomic hybridization (CGH) is used to screen for chromosomal copy number variations such as gene gain, loss, amplification, and deletion. This technique can provide information about genetic instability and chromosomal rearrangements. However, the low resolution of 5-10 Mb is a caveat with conventional CGH. cDNA microarray-based CGH is a useful technique for achieving higher resolution for the detection of genomic aberrations. Pharmacogenomic markers, in combination with clinical factors such as initial hemoglobin level, may be useful for predicting S-1 treatment-induced anemia. Prospective genomic and clinical validation of this model may provide a predictive model for the clinical application of S-1 treatment.
\end{abstract}

Key words Anemia - S-1 · Pharmacogenomics - Microarray $\mathrm{CGH}$

\section{Introduction}

S-1 is a novel oral dihydropyrimidine dehydrogenase (DPD) inhibitory fluoropyrimidine (DIF) developed from the biochemical modulation of 5-fluorouracil (5FU). S-1 is a triple compound consisting of tegafur (FT), gimestat (CDHP), and otastat potassium (Oxo) at molar ratios of $1: 0.4: 1$, respectively. S-1 bioavailability was improved by the addition of gimestat, which has DPD-

Offprint requests to: H.C. Chung

Received: February 24, 2008 / Accepted: March 10, 2008 inhibiting activity, and otastat potassium, which reduces the gastrointestinal toxicity [1].

Derived from phase I data, Japanese early phase II studies of S-1 adopted a fixed dose of $75 \mathrm{mg}$ twice a day. However, skin rash and diarrhea hindered further conduct of the trial, and the dose was reduced to $50 \mathrm{mg}$ twice a day. In consideration of the safety profiles of the fixed-dose schedule, the dose of the late phase II trials was modified to $80 \mathrm{mg} / \mathrm{m}^{2}$ according to the body surface area (BSA). The applied dose ranged from $64 \mathrm{mg} / \mathrm{m}^{2}$ to $80 \mathrm{mg} / \mathrm{m}^{2}$ with a graded system; $80 \mathrm{mg}$ for BSA less than $1.25 \mathrm{~m}^{2}, 100 \mathrm{mg}$ for BSA $1.25-1.50 \mathrm{~m}^{2}$, and $120 \mathrm{mg}$ for BSA more than $1.5 \mathrm{~m}^{2}$. This BSA-based dosing system differed from the Western dosing system in that it fixed the dosage for patients with a BSA greater than $1.5 \mathrm{~m}^{2}$. As a result, in patients with a BSA of more than $1.5 \mathrm{~m}^{2}$, the actual administered dose is not $80 \mathrm{mg} / \mathrm{m}^{2}$ and there is a risk of underdosing. However, the safety profile using this system is better than with a fixed dosing schedule, and S-1 with this dosing system has been the preferred oral agent for the treatment of gastric cancer in Japan.

Based on the Japanese response evaluation criteria, which include primary gastric cancer as a measurable lesion, S-1 demonstrated excellent activity in patients with advanced gastric cancer, with a response rate of $45 \%-54 \%$ in early phase II Japanese trials [2-4]. In these trials, even though the incidence of overall toxicity was as high as $83 \%$, the toxicity profile was mild, with a less than $10 \%$ incidence of grade III or IV toxicities. And in a post-marketing survey, the incidence of toxicity was $74.1 \%$ with the $80 \mathrm{mg} / \mathrm{m}^{2}$ Japanese dosing system with 4-week treatment and a 2-week rest schedule. This incidence of general toxicity was almost equal to that in the pre-marketing clinical trials. The major reasons for discontinuation of S-1 during the first or second cycle of the treatment were disease symptom progression $(43 \%)$ or toxicities $(33 \%)$. The adverse reactions during each cycle appeared mainly during the $2-3$ weeks after 
the start of treatment [5]. In contrast, the toxicity pattern of S-1 is completely different outside Japan. In a phase I trial conducted in the United States, the clinically recommended dose was $60 \mathrm{mg} / \mathrm{m}^{2}$ a day, because of diarrhea and hyperbilirubinemia. [6]. In one European phase II study, diarrhea caused an immediate dose reduction, from $80 \mathrm{mg} / \mathrm{m}^{2}$ to $70 \mathrm{mg} / \mathrm{m}^{2}$ after the enrollment of only a few patients [7]. In a phase II trial conducted in Korea, which was the first Asian trial outside Japan, the tolerability was really good. In this trial, the initial dose of $70 \mathrm{mg} / \mathrm{m}^{2}$ was increased to $80 \mathrm{mg} / \mathrm{m}^{2}$ because there was no incidence of any grade III or IV toxicity at the $70 \mathrm{mg} / \mathrm{m}^{2}$ dosage. Moreover, in this trial, there was no grade IV toxicity and the major adverse event was anemia [8]. These findings suggest that there may be ethnic differences in the toxicity profiles of S-1 treatment. With the microarray comparative genomic hybridization (CGH) technique, 18 genes have been identified with copy number changes associated with the hemoglobin reduction in response to S-1 treatment [8].

\section{Ethnic differences in S-1 adverse events}

There have been five phase I trials of S-1 monotherapy reported since 2000: one from Europe and four from the United States, each with different treatment schedules
[9-12]. With two doses scheduled per day, the maximum tolerable dose (MTD) ranged between 70 and $90 \mathrm{mg} /$ $\mathrm{m}^{2}$, depending on the treatment duration per cycle ( 2 weeks-4 weeks). With the single-dose treatment, the MTD was $60 \mathrm{mg} / \mathrm{m}^{2}$, regardless of the treatment duration ( 3 weeks-4 weeks). The most common doselimiting toxicity (DLT) in Caucasians was diarrhea, regardless of the treatment schedule, duration, or dosage (Table 1). During the 2-week treatment and 1-week rest cycle, there were no grade IV toxicities, even with diarrhea as the DLT [12].

There have been five phase II trials of S-1 monotherapy since 1998: three from Japan, one from Europe, and one from Korea [2-4, 7, 8]. All the trials involved a schedule of two doses per day, with 4-week treatment duration in each cycle and a 1-week rest period in Europe and a 2-week rest period in Asia. The major toxicities in Asian patients were anemia and granulocytopenia, whereas diarrhea was the most common toxicity in European patients (Table 2).

When we compared the toxicities among Korean $\left(70 \mathrm{mg} / \mathrm{m}\right.$ and $\left.80 \mathrm{mg} / \mathrm{m}^{2}\right)$, Japanese and European $\left(70 \mathrm{mg} / \mathrm{m}^{2}\right.$ and $80 \mathrm{mg} / \mathrm{m}^{2}$ ) patients, the incidence of grade I-II anemia was similar for European and Korean patients. But grade III-IV anemia was highest in Korean patients. The incidence of grade I-II leukopenia was similar in patients from Korea, Japan, and Europe. But the incidence of grade IV leukopenia was relatively low

Table 1. Comparison of dose-limiting toxicity in phase I trials of S-1 monotherapy

\begin{tabular}{lccccc}
\hline & 2000 & 2002 & 2003 & 2004 & 2007 \\
\hline Site & Europe & USA & USA & USA & USA \\
Schedule & $4+1$ & $3+1$ & $4+1$ & $4+1$ & $2+1$ \\
Daily dose & Twice & Single & Twice & Single & Twice \\
MTD & $90 \mathrm{mg} / \mathrm{m}^{2}$ & $60 \mathrm{mg} / \mathrm{m}^{2}$ & $70 \mathrm{mg} / \mathrm{m}^{2}$ & $60 \mathrm{mg} / \mathrm{m}^{2}$ & $70 \mathrm{mg} / \mathrm{m}^{2}$ \\
CRD & $80 \mathrm{mg} / \mathrm{m}^{2 \mathrm{a}}$ & $50 \mathrm{mg} / \mathrm{m}^{2}$ & $60 \mathrm{mg} / \mathrm{m}^{2}$ & $50 \mathrm{mg} / \mathrm{m}^{2}$ & $60 \mathrm{mg} / \mathrm{m}^{2}$ \\
DLT & $70 \mathrm{mg} / \mathrm{m}^{2 \mathrm{~b}}$ & Diarrhea, fatigue, & Diarrhea, neutropenia, \\
& Diarrhea & hyperbilirubin-emia & Diarrhea, anorexia & Diarrhea, anorexia \\
& & anorexia &
\end{tabular}

MTD, maximum tolerable dose; CRD, clinically recommended dose; DLT, dose-limiting toxicity

${ }^{\text {a }}$ For chemotherapy-naïve patients

${ }^{\mathrm{b}}$ For previously treated patients

Table 2. Comparison of toxicities in phase II trials of S-1 monotherapy

\begin{tabular}{|c|c|c|c|c|c|}
\hline & 1998 & 1999 & 2000 & 2003 & 2007 \\
\hline Site & Japan & Japan & Japan & Europe & Korea \\
\hline Treatment/ & $4 / 2$ & $4 / 2$ & $4 / 2$ & $4 / 1$ & $4 / 2$ \\
\hline Rest (weeks) & & & & & \\
\hline Daily dose & Twice & Twice & Twice & Twice & Twice \\
\hline Dose & $80 \mathrm{mg} / \mathrm{m}^{2}$ & $100-150 \mathrm{mg}$ & $80 \mathrm{mg} / \mathrm{m}^{2}$ & $\begin{array}{l}80 \mathrm{mg} / \mathrm{m}^{2 \mathrm{a}} \\
70 \mathrm{mg} / \mathrm{m}^{2 \mathrm{~b}}\end{array}$ & $\begin{array}{l}70 \mathrm{mg} / \mathrm{m}^{2 \mathrm{a}} \\
80 \mathrm{mg} / \mathrm{m}^{2 b}\end{array}$ \\
\hline Toxicity & Anemia, leucopenia & Anemia, leucopenia & Anemia, leukopenia & Diarrhea & Anemia \\
\hline
\end{tabular}

${ }^{\mathrm{a}}$ Initial starting dosage

${ }^{\mathrm{b}}$ Modified dosage 
Table 3. Comparison of major toxicities in different countries in phase II trials (percentages)

\begin{tabular}{|c|c|c|c|c|c|c|c|c|}
\hline & \multicolumn{4}{|c|}{ Japan } & \multicolumn{2}{|c|}{ Europe } & \multicolumn{2}{|c|}{ Korea } \\
\hline & Early II & Late II & II & PMS & $70 \mathrm{mg} / \mathrm{m}^{2}$ & $80 \mathrm{mg} / \mathrm{m}^{2}$ & $70 \mathrm{mg} / \mathrm{m}^{2}$ & $80 \mathrm{mg} / \mathrm{m}^{2}$ \\
\hline \multicolumn{9}{|l|}{ Grade I-II } \\
\hline Anemia & 36 & 26 & 30 & 19 & 88 & 95 & 87 & 68 \\
\hline Leukopenia & 54 & 38 & 44 & 23 & 45 & 34 & 13 & 36 \\
\hline Thrombocytopenia & 7 & 30 & 6 & 7 & 14 & 26 & 3 & 3 \\
\hline Mucositis & 11 & 24 & 12 & 12 & 26 & 5 & 16 & 29 \\
\hline Diarrhea & 11 & 10 & 6 & 14 & 24 & 13 & 26 & 26 \\
\hline Anorexia & 18 & 10 & - & 20 & 10 & 13 & 71 & 47 \\
\hline Hyperbilirubinemia & - & - & - & 12 & - & - & 10 & 10 \\
\hline \multicolumn{9}{|l|}{ Grade III-IV } \\
\hline Anemia & 11 & 6 & 4 & 6 & 6 & - & 10 & 16 \\
\hline Leukopenia & 11 & 2 & 2 & 3 & 1 & 3 & 3 & - \\
\hline Thrombocytopenia & 7 & 6 & - & 2 & 10 & 5 & 3 & - \\
\hline Stomatitis & - & - & - & 1 & - & - & - & - \\
\hline Diarrhea & 7 & 2 & 2 & 2 & 4 & 8 & - & 7 \\
\hline Anorexia & 11 & 2 & - & 6 & - & - & 3 & 3 \\
\hline Hyperbilirubinemia & - & - & - & - & - & - & - & 7 \\
\hline
\end{tabular}

Table 4. Comparison of major toxicities in 4-2 and 2-1 week schedules in Korean patients (percentages)

\begin{tabular}{lccccc}
\hline & \multicolumn{2}{c}{$4-2$ Schedule } & & \multicolumn{2}{c}{$2-1$ Schedule } \\
\cline { 2 - 3 } \cline { 5 - 6 } & All grades & Grade III-IV & & All grades & Grade III-IV \\
\hline Anemia & 85 & 13 & & 65 & 6 \\
Leukopenia & 33 & 2 & & 35 & 6 \\
Neutropenia & 24 & 5 & & 37 & 10 \\
Thrombocytopenia & 8 & 2 & & 15 & 4 \\
Mucositis & 19 & 0 & & 37 & 14 \\
Diarrhea & 27 & 3 & & 39 & 14 \\
Anorexia & 64 & 3 & & 81 & \\
\hline
\end{tabular}

in Korean patients who received the highest dosage ever used for treatment. The incidence of grade I-II diarrhea was slightly higher in Korean and European patients. At $80 \mathrm{mg} / \mathrm{m}^{2}$, there was no difference in grade III-IV diarrhea between Korean and European patients, but at the $70 \mathrm{mg} / \mathrm{m}^{2}$ dose, diarrhea was slightly more common in European patients compared to Korean and Japanese patients (Table 3).

In a small Japanese retrospective study comparing a 4- 2-week schedule (4-week treatment and 2-week rest) and a 2-1-week schedule (2-week treatment and 1-week rest), the incidence of overall toxicity was lower for the 2 - 1 -week schedule ( $77 \%$ versus $93 \%$ ), while the response rates were similar in the two schedules $(23 \%$ versus $21 \%$ ) [13]. Anemia was the major toxicity in a phase II trial conducted with the 2-1-week schedule in Korean patients who had a poor performance status [14]. As this trial was performed in patients with a poor performance status, grade III-IV toxicities (except for anemia) were more common than those seen in a previ- ous trial in Korean patients treated with the 4- 2-week schedule (Table 4).

Potential ethnic differences in S-1 tolerance and toxicity may be explained by ethnic differences in S-1 metabolism. Myelosuppression was the main DLT that precluded dose escalation in Japan, while gastrointestinal and skin toxicities were the major DLTs in Caucasians. A pharmacokinetic (PK) profile study of 5-FU, tegafur, CDHP, and Oxo was performed during cycles 1 and 3 in Korean patients [8]. The PK profile showed dose dependency for the $70 \mathrm{mg} / \mathrm{m}^{2}$ to $80 \mathrm{mg} / \mathrm{m}^{2}$ doses. But the AUC of 5-FU increased only marginally, suggesting that the conversion of FT to 5-FU was saturated at the $80 \mathrm{mg} / \mathrm{m}^{2}$ dosage. This conversion level was similar to that seen in the Japanese population [15]. As the Japanese $80 \mathrm{mg} / \mathrm{m}^{2}$ dose is equivalent to the Korean $70 \mathrm{mg} / \mathrm{m}^{2}$ dose with dose rounding, the PK profile for Japanese at the $80 \mathrm{mg} / \mathrm{m}^{2}$ dose was quite similar to the Korean PK profile at the $70 \mathrm{mg} / \mathrm{m}^{2}$ dose. The only difference was a trend for a higher blood Oxo level in 
Japanese patients compared to Korean patients, which may have resulted from less absorption of Oxo from the intestine. Further studies using mucosal biopsy and measurement of the Oxo level in the intestinal mucosa could prove the hypothesis of ethnic differences in the intestinal absorption of Oxo. It is not surprising that that Korean PK profiles for S-1 and its components were more similar to those of the Japanese rather than Caucasians; however, this PK study [8] did not explain the discrepancy in adverse events observed between Korean and Japanese patients, thus warranting a pharmacogenomic study using genomic DNA.

\section{Pharmacogenomic study using cDNA microarray CGH}

Conventional comparative genomic hybridization (CGH) technology was developed to screen for chromosomal alterations on a genome-wide scale. However, the resolution range with conventional CGH is only 3$10 \mathrm{Mb}$ [16]. Microarray technology allows for the simultaneous measurement of a large number of genes at the single-gene level. Array-based CGH combines microarray technology with conventional $\mathrm{CGH}$ to identify a large quantity of genetic alterations at the wholechromosome level $[16,17]$. Array-CGH technology is classified into three types based on the types of probes used: bacterial artificial chromosome (BAC), phage artificial chromosome (PAC), and cDNA or oligonucleotide array CGH. Initially, BAC array CGH consisted of 2400 clones covering the whole genome, and thus the resolution was approximately $1.0 \mathrm{Mb}$ [18]. As a result of continuous technical development, the BAC array at present has been expanded to include 30000 clones for wider coverage of the whole genome [19]. However, BAC array CGH still has problems in terms of experimental time, cost, and resolution limitation. Microarray CGH using cDNA or oligonucleotides can increase the resolution level to the single gene $[17,20]$.

In microarray $\mathrm{CGH}$, the genomic DNA from a patient is compared to reference genomic DNA (from placenta) with different color makers (Fig. 1). A pharmacogenomic study can be done using both genomic DNA from peripheral blood mononuclear cells and tumor DNA from cancer. While somewhat controversial, the genomic DNA is considered to represent the genetic information from the normal tissue, not from the tumor tissue [21]. Generally, the normal tissue is used for toxicity assay and the tumor tissue is used for tumor response assay.

It is well known that most anticancer agents directly suppress hematopoietic stem cells or indirectly suppress the microenvironment of the bone marrow. However, without evidence of bleeding, it is not common that anemia alone, without any leucopenia or thrombocytopenia, is the unique chemotherapy-induced bone marrow suppression phenotype. There have been several reports about 5-FU and uracil-tegafur (UFT)associated hemolytic anemia [22]. In these patients, drug-induced hemolytic anemia was usually associated with long-term exposure, with accompanying clinical symptoms such as dark-colored urine, jaundice, and hepatosplenomegaly, and abnormal laboratory findings. In both Korean and Caucasian patients, several patients have presented with hyperbilirubinemia, but these patients did not show any anemia [6]. The pathophysiology of hyperbilirubinemia after S-1 treatment is unknown. One possible explanation is the saturation of glucuronyltransferase enzymatic activity or the hepatobiliary transportation of S-1, which has no direct correlation with anemia [23, 24].

S-1 treatment-related anemia appears early during the treatment period. Thirteen percent of the patients had grade III anemia at least once during the treatment course, and $42 \%$ of the patients experienced grade IIIII anemia during the first cycle. The overall incidence of anemia in all patients was relatively constant throughout the treatment cycles [8]. In Korean patients with colorectal cancer, the most common hematologic adverse event was anemia without evidence of bleeding, which occurred in $50 \%$ of the patients. And in these patients, the S-1 treatment schedule was 2-week treatment with a 1-week rest cycle [25]. When the PK profiles were similar in Korean, Japanese, and Caucasian patients and there was no definite evidence of bleeding or hemolysis, there was some evidence of genetic involvement in the S-1 treatment-induced anemia; the anemia occurred continuously after treatment and resolved with the cessation of S-1 treatment, there was interpatient variability in the rapidity of anemia occurrence in each cycle, and gradual macrocytosis occurred with S-1 treatment, possibly reflecting deranged DNA synthesis and mitosis. Because there were no known genes correlated with either anemia or S-1 treatmentinduced anemia, we utilized a pharmacogenomic approach to compare the whole genomes of patients with hemoglobin reduction and patients without such reduction after S-1 treatment. As the mean hemoglobin reduction per cycle was 1.0, microarray based CGH was done comparing two groups of patients: patients with mild hemoglobin reduction (MRG; less than 1.0 per cycle) versus those with severe hemoglobin reduction (SRG; more than 1.0 per cycle). The hemoglobin reduction velocity was defined as the slope, which is the difference between the hemoglobin levels $\left(\mathrm{Hb}_{\text {initial }}-\mathrm{Hb}_{\text {nadir }}\right)$ divided by the number of S- 1 cycles during which the initial anemia occurred. The microarray CGH was done in a sex-matched design [26]. The signal intensity of each spot was transformed as the $\log _{2}$ red-to-green 
$(\mathrm{R} / \mathrm{G})$ ratio. Whole microarray spots were mapped on each chromosomal location using SOURCE (http://genome-www5.stanford.edu/cgi-bin/source/ sourceSearch) and DAVID (http://apps1.niaid.nih.gov/ david/). Genes were selected with two different criteria, which is a different way of mRNA expression profiling. First, genes with copy number variations defined as an amplification $\left[\log _{2}(R / G)>0.68\right]$ or a deletion $\left[\log _{2}(R / G)\right.$ $<-0.68$ ] were selected (Fig. 2). Second, genes varying in copy number in more than $30 \%$ of the patients were selected $[27,28]$. Theoretically, the $\log _{2}$ ratio with a single copy change of each gene in microarray CGH is supposed to be 1.0. But the experimental value for

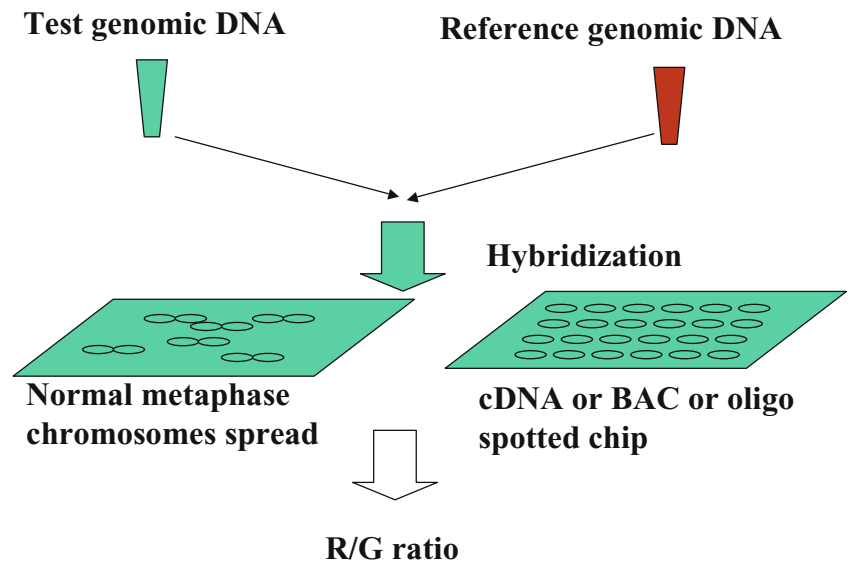

Fig. 1. Schematic comparison of conventional comparative genomic hybridization $(\mathrm{CGH})$ versus microarray CGH. BAC, bacterial artificial chromosome; $R$, red; $G$, green genes with a single copy change showed wide variation. For the sex chromosomes, a $\log _{2}$ ratio of $0.22-0.28$ was suggested for a single copy change [29, 30]. With an indirect study design, ranges of $0.2-0.6$ had been suggested for a single copy change $[31,32]$ and a $\log _{2}$ ratio of 0.68 was suggested as the criterion for genome alterations, such as duplicated or deleted gene changes, regardless of differences in microarray study design (direct, indirect, sex-matched, sex-mismatched; Fig. 3) [28]. The selected genes were then mapped on each chromosome (Fig. 4). When genes with copy number variation are selected, univariate analysis can be performed using clinical factors and selected genes to define the factors associated with hemoglobin reduction. Then a logistic regression model can be built for predicting hemoglobin reduction, using the selected factors or genes (Fig. 5). The initial hemoglobin level and three selected genes were reported with $92 \%$ prediction accuracy using the final regression model with an AUC of 0.98 [8]. Among the selected genes, Grb7 was reported to participate in the maturation of erythroid cells, and the estrogen receptor beta gene was associated with the differentiation of pluripotent hematopoietic cells $[33,34]$.

There have been some controversial reports that describe a correlation between toxicity and patient survival. Breast cancer patients with hematologic toxicity have longer survival than patients without toxicity. Patients with non-small-cell lung cancer with neutropenia also have longer survival than those without neutropenia. In contrast, gastric cancer patients with moderate neutropenia have longer survival than patients with

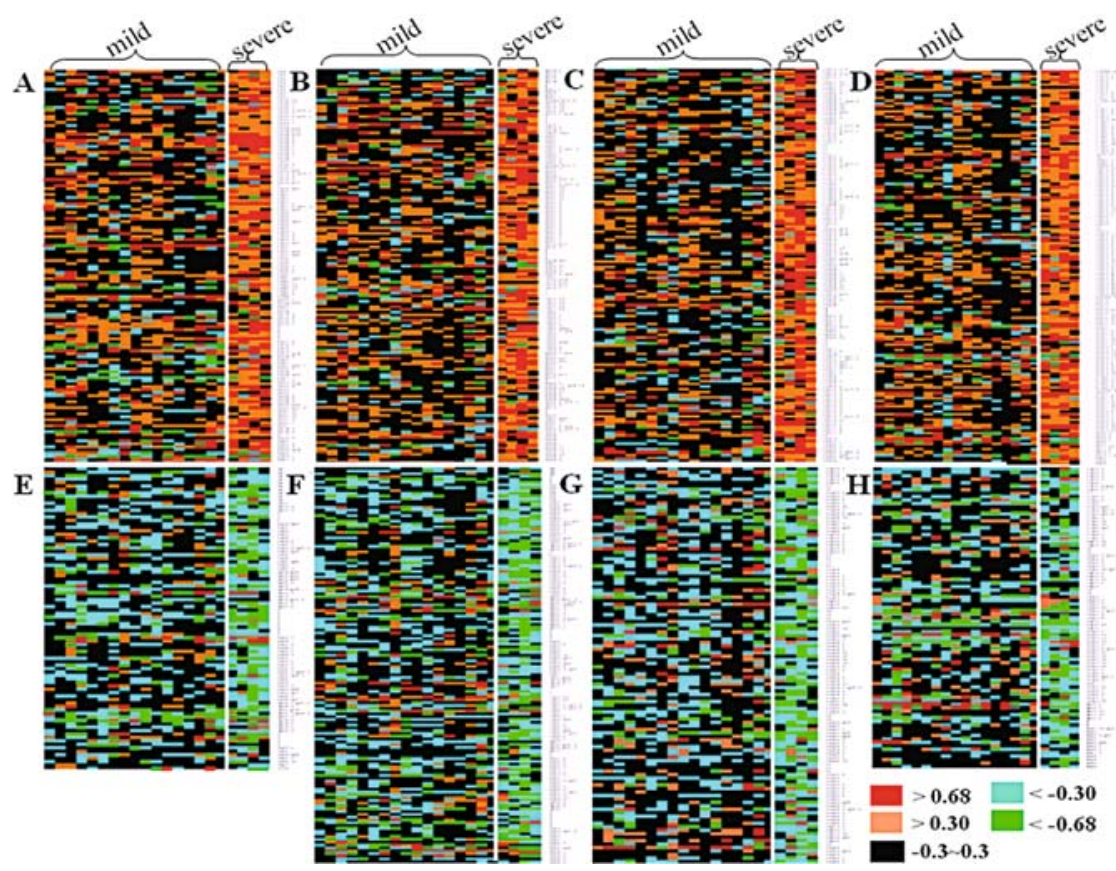

Fig. 2. Gene selection in patients with mild versus those with severe anemia. Parts $A-H$ indicate genes in whole chromosome 


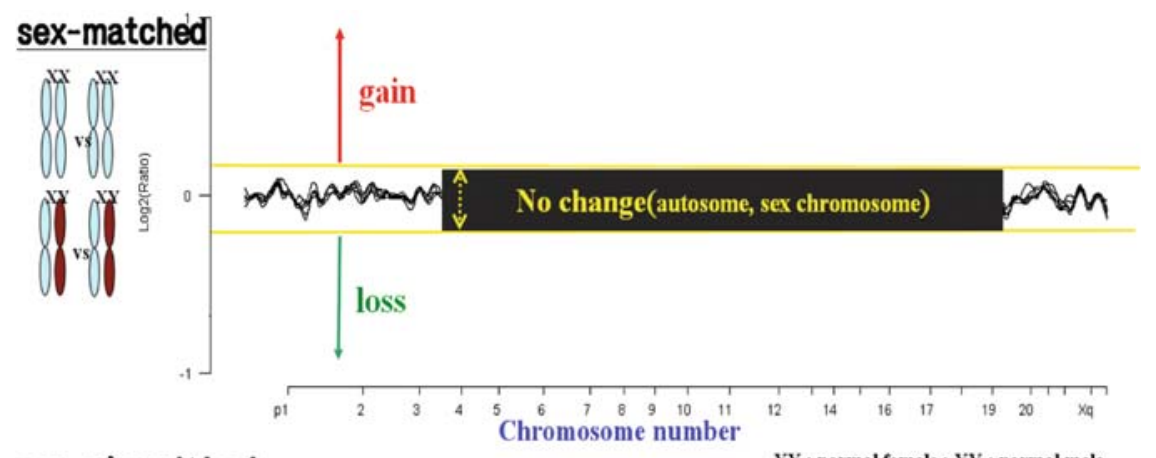

sex-mismatched
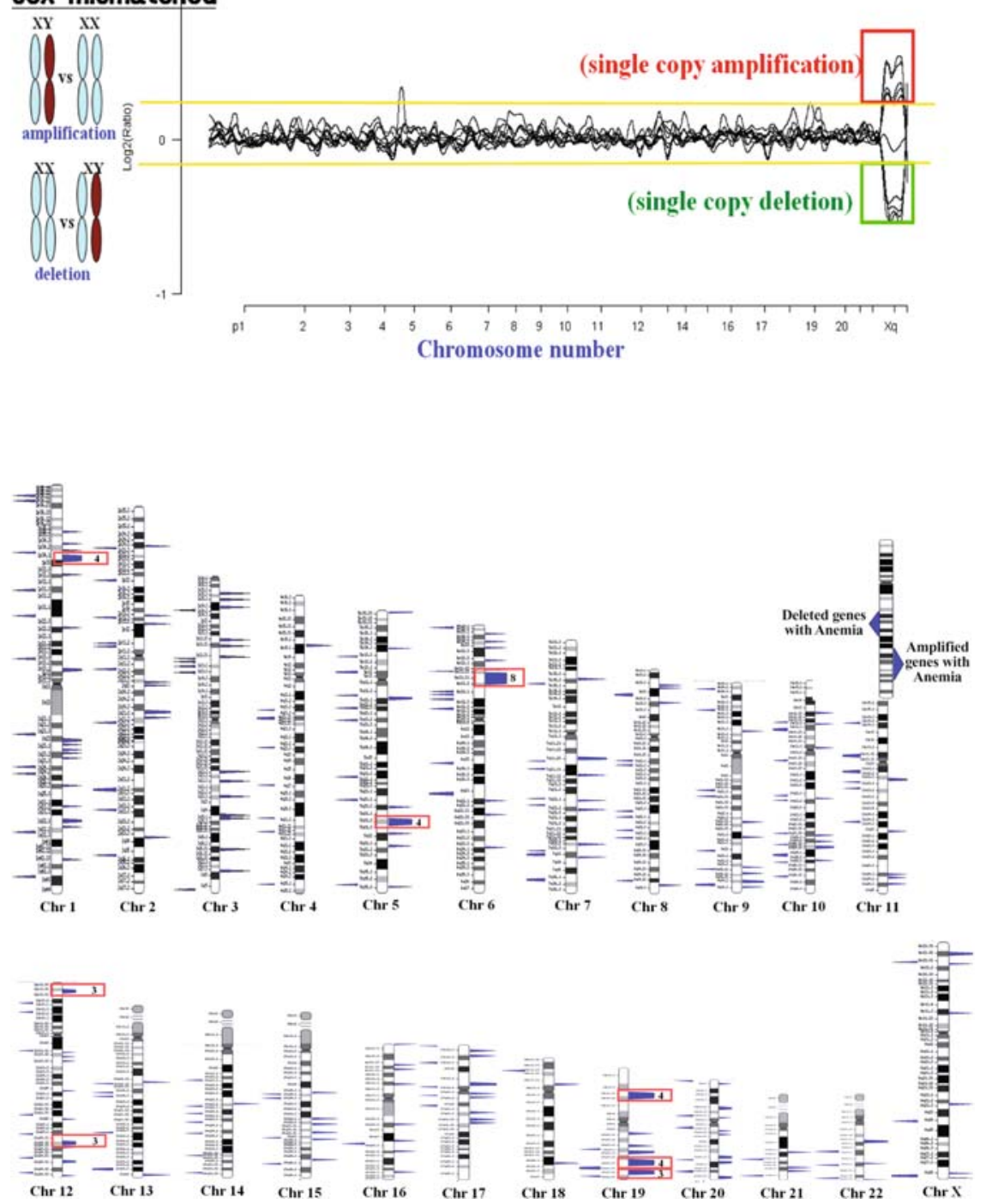

Fig. 3. Comparison of sex-matched and sex-mismatched designs for microarray $\mathrm{CGH}$
Fig. 4. Chromosomal location of selected genes with different frequencies mild or severe neutropenia. However, there may be false associations in these data; for example, patients with poor survival may have shorter treatment periods and show less toxicity, whereas patients with longer survival may have longer treatment periods and show more toxicity. For a predictive study, this kind of clinical bias must be controlled for in the study design.

\section{Future directions}

For the validation of the genes selected, more studies are required, such as: (1) a prospective comparison in clinically matched patients with and without anemia, (2) validation of the selected genes from independent patients, and (3) an exclusion study of drug metabolism- 


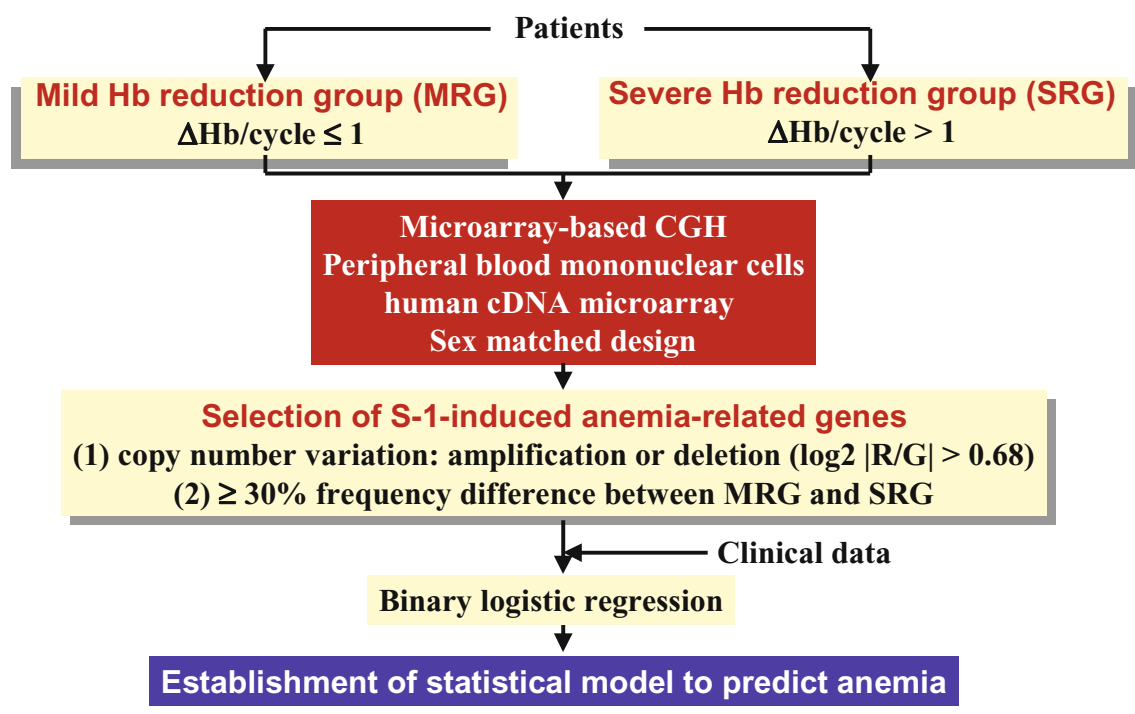

Fig. 5. Scheme for pharmacogenomic approach. $H b$, hemoglobin related genes, such as the cytochrome p450 family ( $C Y P$ $2 A 6)$ or the $D P D$ gene, in patients with anemia. The utility of pharmacogenomic approaches to explain the ethnic variability in S-1-induced toxicity remains speculative and can be optimized through prospective validation.

\section{References}

1. Shirasaka T, Shimamoto Y, Ohshima H, Yamaguchi M, Kato T, Yonemura K, et al. Development of a novel form of an oral 5fluorouracil derivative (S-1) directed to the potentiation of the tumor selective cytotoxicity of 5-fluorouracil by two biochemical modulators. Anticancer Drugs 1996;7:548-57.

2. Sakata Y, Ohtsu A, Horikoshi M, Sugimachi K, Mitachi Y, Taguchi T. Late phase II study of novel oral fluoropyrimidine anticancer drug S-1 (1 M tegafur-0.4 M gimestat- $1 \mathrm{M}$ otastat potassium) in advanced gastric cancer patients. Eur J Cancer 1998:34:1715-20.

3. Koizumi W, Kurihara M, Nakano S, Hasegawa K. Phase II study of S-1, a novel oral derivative of 5-fluorouracil, in advanced gastric cancer. Oncology 2000;58:191-7.

4. Sugomachi K, Maehara Y, Horikoshi N, Shimada Y, Sakata Y, Mitachi Y, et al. An early phase II study of oral S-1, a newly developed 5-fluorouracil derivative for advanced and recurrent gastrointestinal cancers. Oncology 1999;57:202-10.

5. Nagashima F, Ohtsu A, Yoshida S, Ito K. Japanese nationwide post-marketing survey of S-1 in patients with advanced gastric cancer. Gastric Cancer 2005;8:6-11.

6. Hoff PM, Saad ED, Ajani JA, Lassere Y, Wenske C, Medqvesy D, et al. Phase I study with pharmacokinetics of S-1 on an oral daily schedule for 28 days in patients with solid tumors. Clin Cancer Res 2003;9:134-42.

7. Chollet P, Schoffski P, Weigang-Köhler K, Schellens JH, Cure H, Pavlidis N, et al. Phase II study with S-1 in chemotherapy-naïve patients with gastric cancer. A trial performed by the EORTC early clinical studies group (ECSG). Eur J Cancer 2003;39: 1264-70.

8. Jeung HC, Rha SY, Kim HK, Lim HY, Kim S, Kim SY, et al. Multi-institutional phase II study of S-1 monotherapy in advanced gastric cancer with pharmacokinetic and pharmacogenomic evaluations. Oncologist 2007;12:543-54.
9. Van Groeningen CJ, Peters GJ, Schornagel JH, Gall H, Noordhuis P, de Vries MJ, et al. Phase I clinical and pharmacokinetic study of oral S-1 in patients with advanced solid tumors. J Clin Oncol 2000;18:2772-9.

10. Chu QSC, Hammond LA, Schwartz G, Ochoa L, Rha SY, Denis $\mathrm{L}$, et al. Phase I and pharmacokinetic study of the oral fluoropyrimidine S-1 on a once-daily-for-28-day schedule in patients with advanced malignancies. Clin Cancer Res 2004;10:4913-21.

11. Cohen SJ, Leichman CG, Yeslow G, Beard M, Proefrock A, Roedig B, et al. Phase I and pharmacokinetic study of once daily oral administration of S-1 in patients with advanced cancer. Clin Cancer Res 2002;8:2116-22.

12. Zhu AX, Clark JW, Ryan DP, Meyerhardt JA, Enzinger PC, Earle CC, et al. Phase I and pharmacokinetic study of S-1 administered for 14 days in a 21-day cycle in patients with advanced upper gastrointestinal cancer. Cancer Chemother Pharmacol 2007:59:285-93.

13. Kimura Y, Kikkawa N, Iijima S, Kato T, Naoi Y, Hayashi T, et al. A new regimen for S-1 therapy aiming at adverse reaction mitigation and prolonged medication by introducing a 1-week drug-free interval after each 2-week dosing session: efficacy and feasibility in clinical practice. Gastric Cancer 2003;6(Suppl 1): 34-39.

14. Jeung HC, Rha SY, Shin SJ, Ahn JB, Noh SH, Roh JK, et al. A phase II study of S-1 monotherapy administered for 2 weeks of a 3-week cycle in advanced gastric cancer patients with poor performance status. Br J Cancer 2007;97:458-63.

15. Yoshida R, Nakajima M, Nishimura K, Tokudome S, Kwon JT, Yokoi T. Effects of polymorphism in promoter region of human CYP2A6 gene (CYP2A6*9) on expression level of messenger ribonucleic acid and enzymatic activity in vivo and in vitro. Clin Pharmacol Ther 2003;74:69-76.

16. Kallioniemi A, Kallioniemi OP, Sudar D, Rutovitz D, Gray JW, Waldman F, et al. Comparative genomic hybridization for molecular cytogenetics analysis of solid tumors. Science 1992; 258 : 818-21.

17. Carvalho B, Ouwerkerk E, Meijer GA, Ylstra B. High resolution microarray comparative genomic hybridization analysis using spotted oligonucleotides. J Clin Pathol 2004;57:644-6.

18. Snijders AM, Nowak N, Segraves R, Blackwood S, Brown N, Conroy J, et al. Albeertson DG. Assembly of microarrays for genome-wide measurement of DNA copy number. Nat Genet 2001;29:264-4.

19. Ishkanian AS, Malloff CA, Watson SK, DeLeeuw RJ, Chi B, Coe BP, et al. A tiling resolution DNA microarray with complete coverage of the human genome. Nat Genet 2004;36:299-303. 
20. Van den Ijssel P, Tijssen M, Chin SF, Eijk P, Carvalho B, Hopmans $\mathrm{E}$, et al. Human and mouse oligonucleotide-based array CGH. Nucleic Acids Res 2005;33:e192.

21. Desai AA, Innocenti F, Ratain MJ. Pharmacogenomics: road to anticancer therapeutics nirvana? Oncogene 2003;22:6621-8.

22. Zurita SAJ, Navarro GM, Espanol I, Fernandez OA. UFTinduced hemolytic anemia. Cancer Chemother Pharmacol 2001; 47:280-1.

23. Innocenti F, Liu W, Chen P, Desai AA, Das S, Ratain MJ. Haplotypes of variants in the UDP-glucuronosyltransferase 1A9 and 1A1 genes. Pharmacogenet Genomics 2005:15:295-301.

24. Shimada T, Yamazaki H, Guengerich FP. Ethnic related differences in coumarin 7-hydroxylation activities catalyzed by cytochrome P4502A6 in liver microsomes of Japanese and Caucasian populations. Xenobiotica 1996:26:395-403.

25. Jeung HC, Rha SY, Cho BC, Yoo NC, Roh JK, Roh WJ, et al. A phase II trial of S-1 monotherapy in metastatic colorectal cancer after failure of irinotecan- and oxaliplatin-containing regimens. Br J Cancer 2005;95:1637-41.

26. Seo MY, Rha SY, Yang SH, Kim SC, Lee GY, Park CH, et al. The pattern of gene copy number changes in bilateral breast cancer surveyed by cDNA microarray-based comparative genomic hybridization. Int J Mol Med 2004:13:17-24.

27. Eisen MB, Spellman PT, Brown PO, Botstein D. Cluster analysis and display of genome-wide patterns. Proc Natl Acad Sci U S A 1998;95:14863-8.

28. Park $\mathrm{CH}$, Jeong HJ, Choi YH, Kim SC, Jeung HC, Park KH, et al. Systematic analysis of cDNA microarray-based CGH. Int J Mol Med 2006;17:261-7.
29. Wilhelm M, Veltman JA, Olshen AB, Jain AN, Moore DH, Presti $\mathrm{JC} \mathrm{Jr}$, et al. Array-based comparative genomic hybridization for the differential diagnosis of renal cell cancer. Cancer Res 2002; 62:957-60.

30. Pollack JR, Perou CM, Alizadeh AA, Eisen MB, Pergamenschikov A, Williams CF, et al. Genome-wide analysis of DNA copy-number changes using cDNA microarrays. Nat Genet 1999; 23:41-6.

31. Peng DF, Sugihara H, Mukaisho K, Tsubosa Y, Hattori T. Alterations of chromosomal copy number during progression of diffusetype gastric carcinomas: meta-phase- and array-based comparative genomic hybridization analyses of multiple samples from individual tumors. J Pathol 2003;201:439-50.

32. Weiss MM, Snijders AM, Kuipers EJ, Ylstra B, Pinkel D, Meuwissen SG, et al. Determination of amplicon boundaries at 20q13.2 in tissue samples of human gastric adenocarcinomas by high resolution microarray comparative genomic hybridization. J Pathol 2003;200:320-6.

33. Olweus J, Terstappen LW, Thompson PA, Lund-Johansen F. Expression and function of receptors for stem cell factor and erythropoietin during lineage commitment of human hematopoietic progenitor cells. Blood 1996;88:1594-607.

34. Shim GJ, Wang L, Andersson S, Nagy N, Kis LL, Zhang Q, et al. Disruption of the estrogen receptor beta gene in mice causes myeloproliferative disease resembling chronic myeloid leukemia with lymphoid blast crisis. Proc Natl Acad Sci U S A 2003; 100:6694-9. 